\title{
Application of Ground Granulate Blast Furnace Slag-Steel Slag Composite Binder in a Massive Concrete Structure under Severe Sulphate Attack
}

\author{
Jin Liu and Dongmin Wang \\ School of Chemical and Environmental Engineering, China University of Mining and Technology, Beijing 100083, China \\ Correspondence should be addressed to Dongmin Wang; wangdongmin-2008@163.com
}

Received 17 May 2017; Accepted 19 July 2017; Published 20 August 2017

Academic Editor: Frederic Dumur

Copyright (C) 2017 Jin Liu and Dongmin Wang. This is an open access article distributed under the Creative Commons Attribution License, which permits unrestricted use, distribution, and reproduction in any medium, provided the original work is properly cited.

\begin{abstract}
A composite mineral binder was prepared by mixing ground granulate blast furnace slag (GGBS) and steel slag (GGBS/steel slag ratios are $1: 1$ or $3: 2$ by mass). The application of a composite binder in a massive concrete structure under severe sulphate attack is discussed by determining the hydration heat, adiabatic temperature increase, compressive strength, elastic modulus, chloride ion permeability, and sulphate attack resistance. The results show that the hydration heat of the composite binder decreases greatly when the cement replacement ratio increases to $50 \%$ at $45^{\circ} \mathrm{C}$. The adiabatic temperature rise of the concrete containing the composite mineral admixture decreases significantly. Concrete containing the composite mineral admixture has a lower early elastic modulus and satisfactory late-age compressive strength. The composite mineral admixture can improve the resistance to chloride ion permeability and sulphate attack resistance of concrete, especially during temperature match curing.
\end{abstract}

\section{Introduction}

According to the American Concrete Institute (ACI), massive concrete is cast in situ to a size capable of addressing the problem of hydration heat, which then causes volume deformation and has to reduce the influence of cracking. The hydration heat from the inner cement inside a mass concrete structure cannot dissipate immediately, causing a large temperature gradient and thermally induced stress cracking in the massive concrete structure $[1,2]$. Therefore, to minimize the risk of cracking in massive concrete structures, high fractions of mineral admixtures are used to reduce the hydration heat of cement and the adiabatic temperature rise of the concrete [3]. Meanwhile, large numbers of massive concrete structures in soil with high saline concentrations suffer severe sulphate attacks, such as concrete foundations with a diameter larger than $1 \mathrm{~m}$, or even $2 \mathrm{~m}$ for transmission line towers. Sulphates are abundant in saline soil and react with $\mathrm{Ca}(\mathrm{OH})_{2}$ and $\mathrm{C}-\mathrm{A}-\mathrm{H}$ to form gypsum and ettringite, respectively, causing volume expansion in concrete [4]. This is especially true when concrete is subjected to dry-wet cycles.
During this process, salt crystallization occurs, which also causes volume expansion and aggravates concrete corrosion [5]. To ensure the durability of massive concrete structures, the design strength of massive concrete is usually higher than 40 or $50 \mathrm{MPa}$.

Steel slag is a by-product from the process that transforms iron into steel [6]. The emission of steel slag makes up 13-20\% of steel production [7]. Steel slag has cementitious properties, and the hydration process and hydration products of steel slag are similar to those of Portland cement (although its hydration activity is much lower than that of Portland cement) [8]. Used as a mineral admixture, steel slag can reduce the hydration heat of cement and significantly decrease the adiabatic temperature rise of concrete $[9,10]$. However, the large particles in steel slag have few cementitious properties, and the interfaces between the large particles of steel slag and calcium silicate hydrate gels are weak points that may induce failures [11]. Additionally, large amounts of steel slag tend to result in a coarser pore structure for the hardened paste [12], yielding a negative effect on the strength and durability of the concrete [13]. In some studies, ground granulate blast furnace 
slag-steel slag composite binder was used as a composite mineral admixture and shown to prolong the setting time of the cement, improve the fluidity of fresh concrete, refine the pore structure of hardened paste, and result in a satisfactory compressive strength for the concrete $[14,15]$. It is worth noting that the effect of the composite binder on decreasing the hydration heat of cement and the adiabatic temperature rise of concrete is more significant than that of fly ash [14].

The pozzolanic reaction of ground granulate blast furnace slag consumes $\mathrm{Ca}(\mathrm{OH})_{2}$, decreasing the amount of gypsum formed by the reaction between sulphate and $\mathrm{Ca}(\mathrm{OH})_{2}$ [4]. Additionally, the C-S-H gels formed by the pozzolanic reaction of the ground granulate blast furnace slag fills the pore structure of the hardened paste, causing the concrete to be denser and better resist sulphate attack $[16,17]$. GGBS and steel slag both are industrial by-products and have reactivity. In this paper, the application of ground granulate blast furnace slag-steel slag composite binder in massive concrete structures under severe sulphate attack is discussed.

\section{Raw Materials and Test Methods}

2.1. Raw Materials. The cement used here was ordinary Portland cement with a specific surface area of $351 \mathrm{~m}^{2} \mathrm{~kg}^{-1}$ and a strength grade of 42.5 , which complied with the Chinese National Standard GB175-2007. Table 1 shows the major chemical components of the cement, GGBS, and steel slag. Figure 1 shows the particle size distributions of the cement, GGBS, and steel slag. The coarse aggregate used was limestone that was crushed to sizes between $5 \mathrm{~mm}$ and $25 \mathrm{~mm}$. The fine aggregate used was natural river sand with a size smaller than $5 \mathrm{~mm}$. To ensure the fluidity of the concrete, polycarboxylate superplasticizer was used. The steel slag was mixed with GGBS as a composite mineral admixture. Considering that both of GGBS and steel slag could be fully utilized and attempt to make concrete obtain a relatively higher performance, the mass ratios of the GGBS to steel slag are $1: 1$ and $3: 2$, which are defined as $\mathrm{A}$ and $\mathrm{B}$, respectively.

2.2. Test Methods. Table 2 lists the mixing proportions for the composite binders used for hydration heat evolution. An isothermal calorimeter was used to test the hydration heat of the composite binders within $72 \mathrm{~h}$ at constant temperatures of $20^{\circ} \mathrm{C}$ and $45^{\circ} \mathrm{C}$, respectively. Table 3 lists the mixing proportions for the concrete. The adiabatic temperature increases for the concrete were tested using a specific adiabatic temperature measuring instrument with an accuracy of $\pm 0.1^{\circ} \mathrm{C}$.

Two curing methods were used for the concrete in this study: (1) standard curing and (2) temperature match curing. For standard curing, the concrete samples were cured in a room with a relative humidity higher than $95 \%$ and a temperature of $20 \pm 1^{\circ} \mathrm{C}$. For temperature match curing, the concrete samples were placed in curing boxes, whose temperatures were adjusted according to the adiabatic temperature rises for the concrete samples. After curing for $7 \mathrm{~d}$, these samples were cooled naturally and placed in a room corresponding to the standard curing condition.

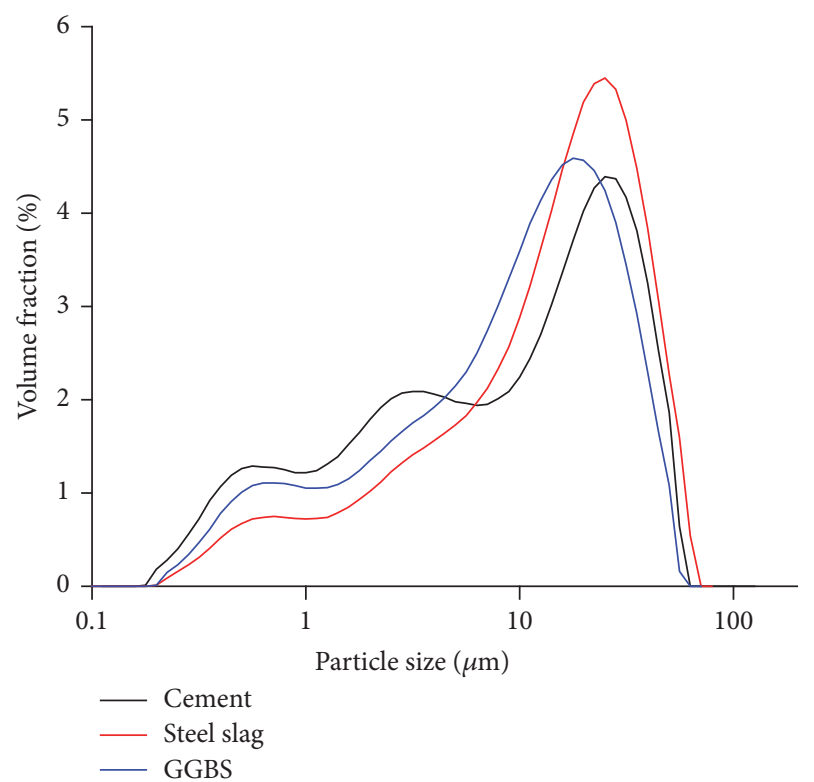

FIGURE 1: The particle size distributions of the cement, GGBS, and steel slag.

Concrete samples with sizes of $10 \times 10 \times 30 \mathrm{~cm}$ were cast for elastic moduli testing at ages of $7 \mathrm{~d}, 28 \mathrm{~d}$, and $90 \mathrm{~d}$. Concrete samples with sizes of $10 \times 10 \times 10 \mathrm{~cm}$ were cast for compressive strength testing at ages of $7 \mathrm{~d}, 28 \mathrm{~d}$, and $90 \mathrm{~d}$. According to ASTM C 1202 "Standard Test Method for Electrical Indication of Concretes Ability to Resist Chloride Ion Penetration," the chloride ion permeability of the concrete was evaluated by measuring the charge passed at ages of $28 \mathrm{~d}$ and $90 \mathrm{~d}$.

The sulphate attack resistance of the concrete was tested using the dry-wet cycle method. The dry-wet cycle test was conducted according to "Chinese National Standard GBT50082-2009 Standard for test methods of long-term performance and durability of ordinary concrete." After standard curing and temperature match curing for $28 \mathrm{~d}$, the concrete samples used for the sulphate attack group were placed into a $5 \%$ sodium sulphate solution and immersed for $15 \mathrm{~h}$. Then, the concrete samples were dried in electric vacuum drying ovens at $80^{\circ} \mathrm{C}$ for $6 \mathrm{~h}$. Finally, the concrete samples were cooled and each dry-wet cycle is $24 \mathrm{~h}$. Concrete samples in the control group were cured using the standard curing conditions. After 90 and 120 cycles of this process, the compressive strengths of both groups were tested, and compressive strength loss rates were calculated using the compressive strengths of the sulphate attack group normalized by those of the control group.

\section{Results and Discussion}

3.1. Hydration Heat and Adiabatic Temperature Rise. Figures 2(a) and 2(b) show the exothermic rate curves and cumulative heat curves during the hydration of plain cement and the composite binders at $20^{\circ} \mathrm{C}$, respectively. As shown in Figure 2(a), as the cement replacement ratio increased, the 
TABLE 1: Chemical compositions of the cement, GGBS, and steel slag (\%).

\begin{tabular}{lcccccrr}
\hline Sample & $\mathrm{SiO}_{2}$ & $\mathrm{Al}_{2} \mathrm{O}_{3}$ & $\mathrm{Fe}_{2} \mathrm{O}_{3}$ & $\mathrm{CaO}$ & $\mathrm{MgO}$ & $\mathrm{MnO}$ & \multicolumn{2}{c}{ Loss } \\
\hline Cement & 22.36 & 7.73 & 3.66 & 57.21 & 3.10 & 2.31 \\
GGBS & 26.65 & 14.25 & 0.62 & 46.83 & 7.61 & 0.27 & 1.86 \\
Steel slag & 19.11 & 7.46 & 18.01 & 43.37 & 5.17 & 2.66 \\
\hline
\end{tabular}

TABLE 2: Mixing proportions for the composite binders used for hydration heat evolution (g).

\begin{tabular}{lcccc}
\hline Samples & Cement & Composite mineral admixture A & Composite mineral admixture B & Water \\
\hline P1 & 100 & 0 & 0 & 40 \\
P2 & 60 & 40 & 0 & 40 \\
P3 & 55 & 45 & 0 & 40 \\
P4 & 50 & 50 & 50 & 40 \\
P5 & 50 & 0 & 40 \\
\hline
\end{tabular}

TABLE 3: Mixing proportions for the concrete $\left(\mathrm{kg} / \mathrm{m}^{3}\right)$.

\begin{tabular}{lcccccc}
\hline Samples & Cement & Composite mineral admixture A & Composite mineral admixture B & Water & Fine aggregates & Coarse aggregates \\
\hline C1 & 380 & 0 & 0 & 152 & 785 & 1083 \\
C2 & 190 & 190 & 0 & 152 & 785 & 1083 \\
C3 & 190 & 0 & 190 & 152 & 785 & 1083 \\
\hline
\end{tabular}

exothermic peak of the composite binder is delayed, and the exothermic peak value of the composite binder decreases. In addition, the exothermic rate of the composite binder is lower than that of the plain cement after approximately $2 \mathrm{~d}$. As shown in Figure 2(b), the cumulative hydration heat of the composite binder is distinctly lower than that of the plain cement within $3 \mathrm{~d}$. These results indicate that the hydration activities of the GGBS and steel slag are much lower than those of the cement during the early stages, which is consistent with previous findings $[8,12,18]$.

Figures 3(a) and 3(b) show the exothermic rate curves and cumulative heat curves during the hydration of plain cement and the composite binders at $45^{\circ} \mathrm{C}$, respectively. The exothermic rate of the composite binder at $45^{\circ} \mathrm{C}$ is clearly higher than that of the composite binder at $20^{\circ} \mathrm{C}$. This high temperature has a significant activation effect on the hydration of the GGBS and steel slag. This is more pronounced for the GGBS, which is more sensitive to high temperatures than other mineral admixtures and cement. Additionally, the hydration degrees of the GGBS and steel slag increase dramatically at higher temperatures [18-20]. Additionally, the hydration heat of the GGBS is so large that the hydration heat of the binder containing $17-40 \%$ fine GGBS is greater than that of plain cement at room temperature, and the hydration heat of the binder containing $30-50 \%$ GGBS is close to or even higher than that of plain cement at $60^{\circ} \mathrm{C}[20,21]$. It is noteworthy that the exothermic rate of the composite binder is greater than that of plain cement after hydration for approximately $10 \mathrm{~h}$. On the one hand, dense and thick C-S-H layers forms when the cement hydrates rapidly at high temperatures, hindering the hydration of the cement at later ages to some extent [22]. On the other hand, the hydration of the GGBS and steel slag promoted by the high temperature contributes significantly to the hydration heat of the composite binder. As shown in
Figure 3(b), the cumulative heat of the binder containing $40 \%$ composite mineral admixture is greater than that of plain cement within $3 \mathrm{~d}$, and the cumulative heat of the binder containing $45 \%$ composite mineral admixture is close to that of plain cement within $3 \mathrm{~d}$. However, when the cement replacement ratio increases to $50 \%$, the cumulative heat of the composite binder is clearly less than that of the plain cement within $3 \mathrm{~d}$. This is because as cement replacement ratio increases, the hydration activity of the composite binder decreases with lower cement content and the activating effect on the hydration of GGBS is weakened with the decrease of $\mathrm{Ca}(\mathrm{OH})_{2}$ in hydration products of cement [23].

The internal temperature of a massive concrete structure is usually higher than room temperature. Therefore, the hydration and exothermic properties of the binder at $45^{\circ} \mathrm{C}$ are more applicable to massive concrete than those of the binder at $20^{\circ} \mathrm{C}$. According to the experimental results for the hydration heat of the binder at $45^{\circ} \mathrm{C}$, the binder containing $50 \%$ composite mineral admixture is feasible for a massive concrete structure in order to minimize the temperature increase.

Figure 4 shows the adiabatic temperature rise curves of plain cement concrete and concrete containing the $50 \%$ composite mineral admixture. As shown in Figure 4, the adiabatic temperatures of the concrete containing $50 \%$ composite mineral admixture increase at a slower rate compared to plain cement concrete. Additionally, the adiabatic temperature increase of the concrete containing $50 \%$ composite mineral admixture is clearly less than that of plain cement concrete within $7 \mathrm{~d}$. The GGBS content of composite mineral admixture $\mathrm{A}$ is less than that of composite mineral admixture $\mathrm{B}$, so the effect of composite mineral admixture A on decreasing the hydration temperature increase is greater than that of composite mineral admixture B. 


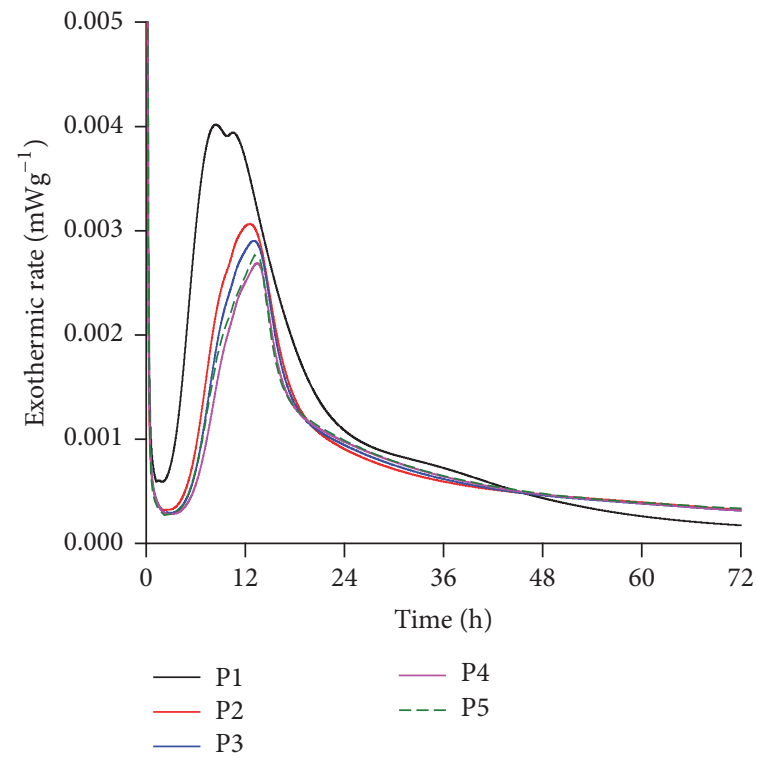

(a)

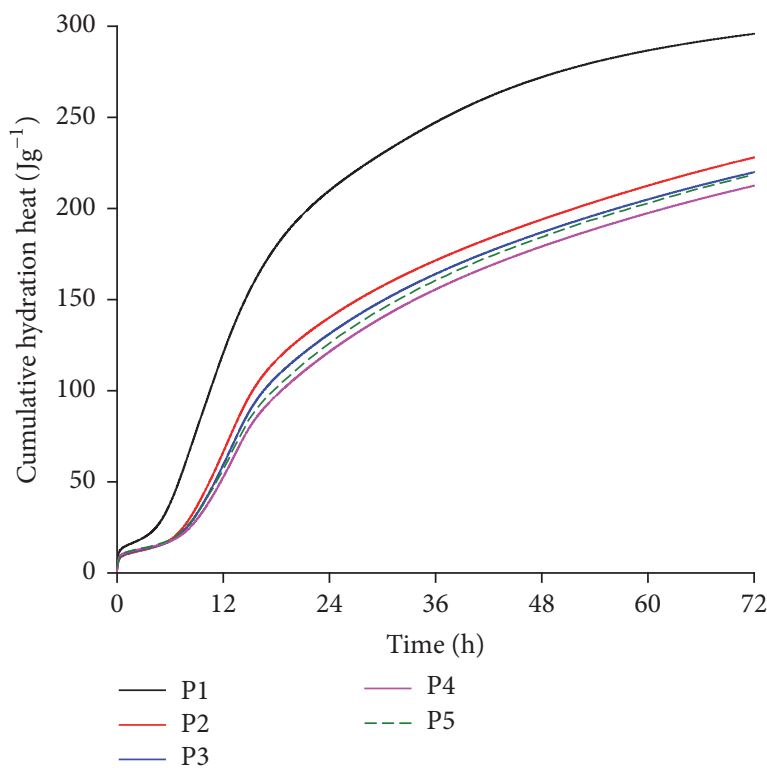

(b)

FIGURE 2: (a) Exothermic rate curves during the hydration of plain cement and composite binders at $20^{\circ} \mathrm{C}$. (b) Cumulative heat curves during the hydration of plain cement and composite binders at $20^{\circ} \mathrm{C}$.

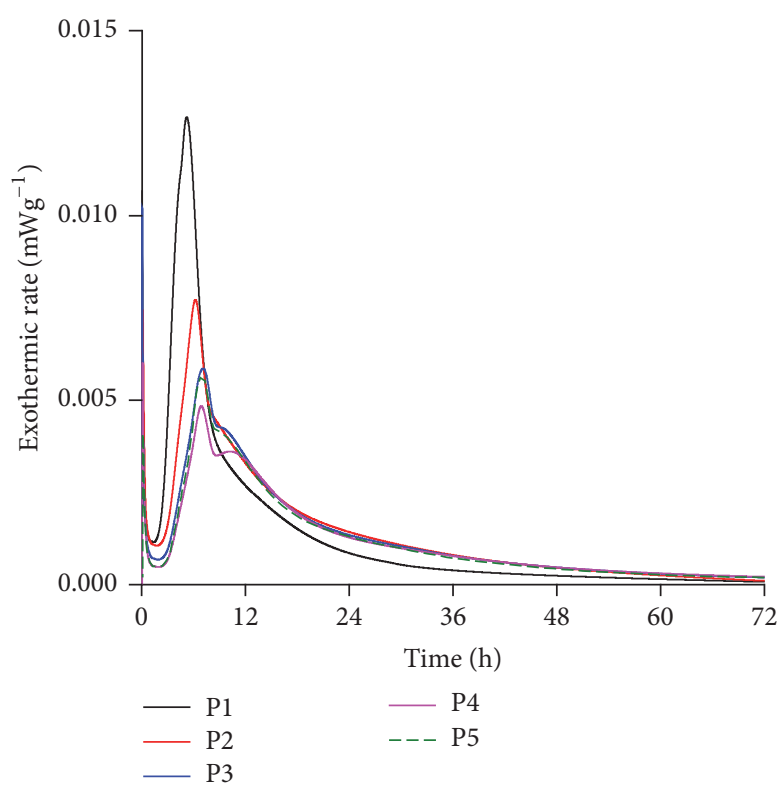

(a)

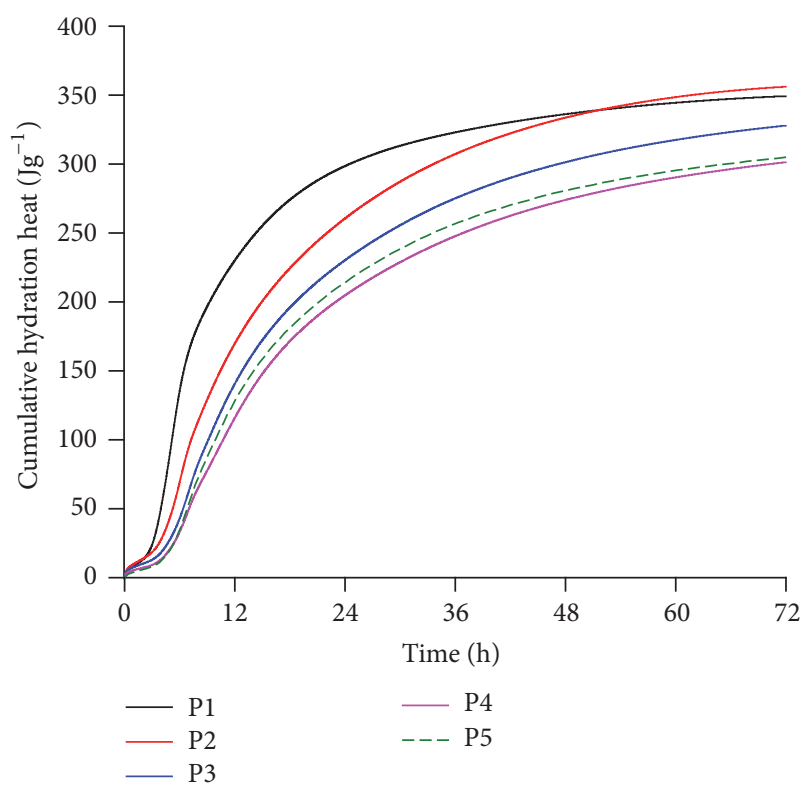

(b)

FIGURE 3: (a) Exothermic rate curves during the hydration of plain cement and composite binders at $45^{\circ} \mathrm{C}$. (b) Cumulative heat curves during the hydration of plain cement and composite binders at $45^{\circ} \mathrm{C}$.

\subsection{Mechanical Property}

3.2.1. Compressive Strength. Figure 5(a) shows the compressive strength of concrete for standard curing. The compressive strength of the concrete containing $50 \%$ composite mineral admixture is significantly less than that of plain cement concrete at $7 \mathrm{~d}$. However, the compressive strength of the concrete containing 50\% composite mineral admixture is close to that of plain cement concrete at $28 \mathrm{~d}$, and the difference in the compressive strength between the plain cement concrete and concrete containing 50\% composite mineral admixture is less than $3.6 \%$ at $90 \mathrm{~d}$. These results indicate that although the early compressive strength of the concrete containing $50 \%$ composite mineral admixture is relatively low, the concrete containing 50\% composite mineral admixture has a higher compressive strength gain rate and reaches a satisfactory 


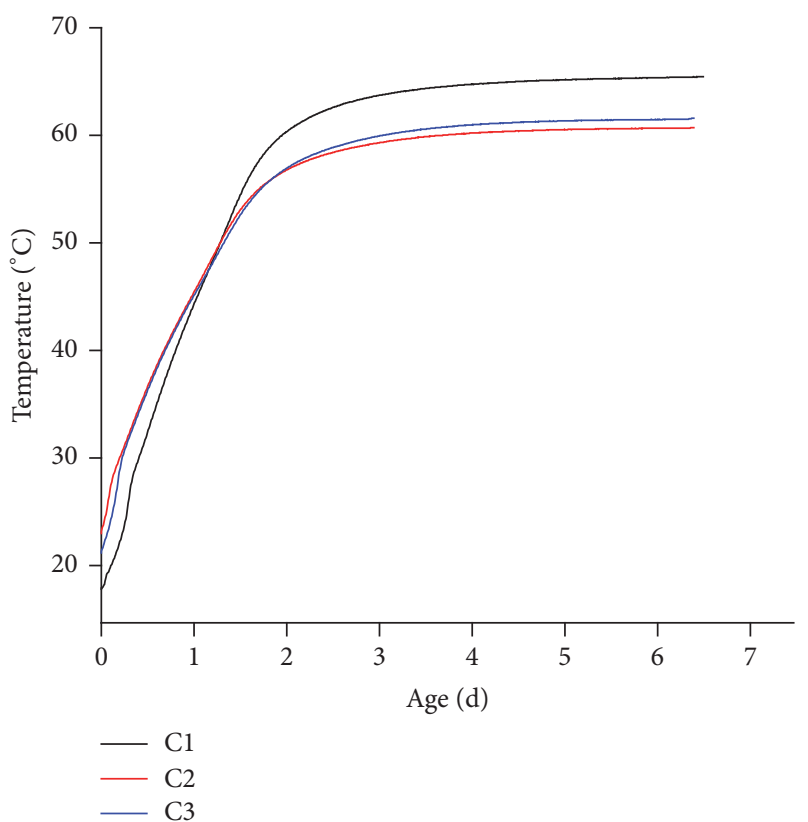

FIgURE 4: Adiabatic temperature rise curves of plain cement concrete and concretes containing 50\% composite mineral admixture.

compressive strength at late ages. Additionally, the GGBS content of composite mineral admixture $B$ is higher than that of composite mineral admixture $\mathrm{A}$, and the compressive strength of the concrete containing composite mineral admixture $\mathrm{B}$ is higher than that of the concrete containing composite mineral admixture $\mathrm{A}$ at all ages.

Figure 5(b) shows the compressive strength of the concrete for temperature match curing. As shown in Figure 5(b), these samples benefited from the activating effect of the high temperature on the hydration of the composite mineral admixture and the compressive strength of the concrete containing $50 \%$ composite mineral admixture is only slightly less than that of the plain cement concrete at $7 \mathrm{~d}$. The compressive strength of the concrete containing $50 \%$ composite mineral admixture is slightly greater than of the plain cement concrete at $28 \mathrm{~d}$, and the compressive strength of the concrete containing 50\% composite mineral admixture is clearly greater than that of plain cement concrete at $90 \mathrm{~d}$. These results indicate that, for temperature match curing, the concrete containing 50\% composite mineral admixture reaches a satisfactory early compressive strength, as well as higher late-age compressive strength, although the compressive strength gain rate of plain cement concrete is low at late ages. This is because concrete cured at a high temperature results in nonuniformly distributed hydration products and a coarser pore structure in hardened paste [24-26]. However, the hydration degree of the mineral admixture increases at high temperatures, and the C-S-H gels produced during the hydration of the mineral admixture fill the pore structure of the hardened paste, as a result of which the negative effect of high temperature on development of compressive strength is weakened and the concrete containing mineral admixture cured at high temperature at early ages has a relatively high compressive strength gain rate $[26,27]$. In addition, the compressive strength of the concrete containing composite mineral admixture B is still greater than for the concrete containing composite mineral admixture A at all ages for temperature match curing.

\subsubsection{Elastic Modulus. Stress is calculated as}

$$
\sigma=E \cdot \varepsilon
$$

where $\sigma$ is stress, $E$ is elastic modulus, and $\varepsilon$ is strain. Stress decreases with the decrease of elastic modulus for a constant strain. For massive concrete, the thermal stress will be relatively low if the elastic modulus is low at early ages, and the risk of thermally induced cracking tends to decrease under lower stress.

Figures 6(a) and 6(b) show the elastic modulus of the concrete for standard and temperature match curing, respectively. The elastic modulus of the concrete containing $50 \%$ composite mineral admixture is clearly less than that of plain cement concrete at $7 \mathrm{~d}$, and the elastic modulus of the concrete containing 50\% composite mineral admixture is still less than that of plain cement concrete at $28 \mathrm{~d}$ and 90 d. As shown in Figure 6(b), although the elastic modulus of the concrete containing 50\% composite mineral admixture is slightly higher than that of plain cement concrete at $90 \mathrm{~d}$, the elastic modulus of the concrete containing $50 \%$ composite mineral admixture is less than that of plain cement concrete at $7 \mathrm{~d}$ and $28 \mathrm{~d}$. These results indicate that the early elastic modulus of the concrete decreases as the composite mineral admixture is added, which is helpful to decrease the thermally induced cracking.

\subsection{Chloride Ion Permeability. According to ASTM C1202,} the chloride ion permeability grade of concrete is "Moderate" if the charge passed is between 2000 and $4000 \mathrm{C}$. The chloride ion permeability grade of concrete is "Low" or "Very low" if the charge passed is between 1000 and $2000 \mathrm{C}$ or less than $1000 \mathrm{C}$, respectively.

Figure 7 (a) shows the chloride ion permeability for the concrete for standard curing. For either $28 \mathrm{~d}$ or $90 \mathrm{~d}$, the charge passed for the concrete containing 50\% composite mineral admixture is clearly less than that for plain cement concrete and the chloride ion permeability grade of the concrete containing 50\% composite mineral admixture is less than that for plain cement concrete. These results indicate that the composite mineral admixture exhibits strong improvement effect on the resistance to chloride ion permeability for the concrete. In addition, the charge passed for the concrete containing composite mineral admixture B is slightly less than for the concrete containing composite mineral admixture $\mathrm{B}$, indicating that composite mineral admixture $\mathrm{B}$ results in a greater resistance to chloride ion permeability of concrete than composite mineral admixture A. This could be explained that the pozzolanic reaction of GGBS consumes $\mathrm{Ca}(\mathrm{OH})_{2}$, leading to the decrease of interconnected pores [28].

Figure 7(b) shows the chloride ion permeability of the concrete for temperature match curing. The charge passed for plain cement concrete for temperature match curing is higher 


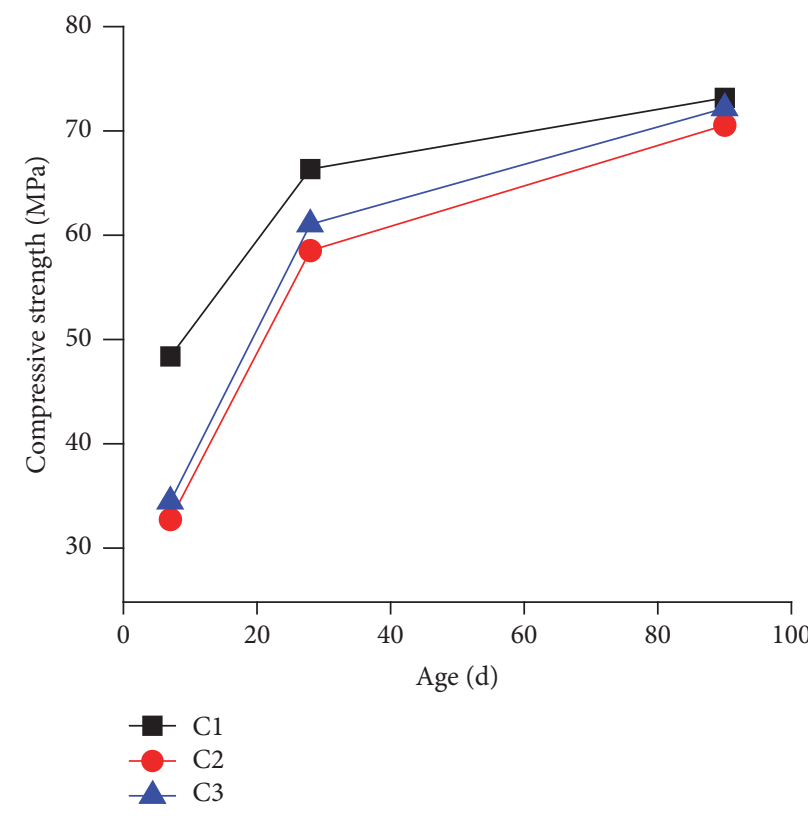

(a)

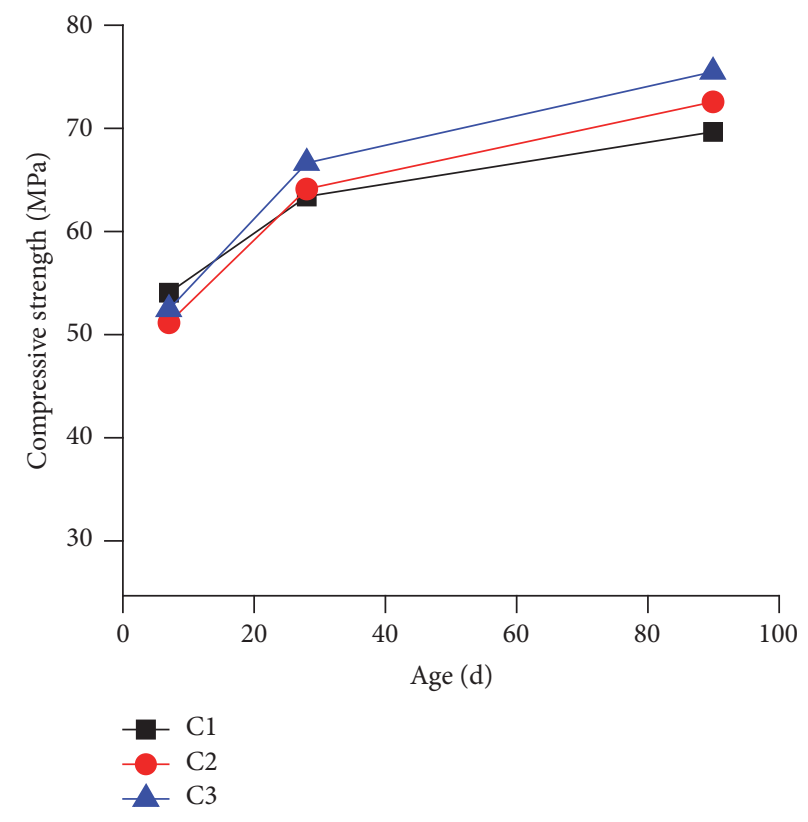

(b)

Figure 5: (a) Compressive strength of concrete for standard curing. (b) Compressive strength of concrete for temperature match curing.

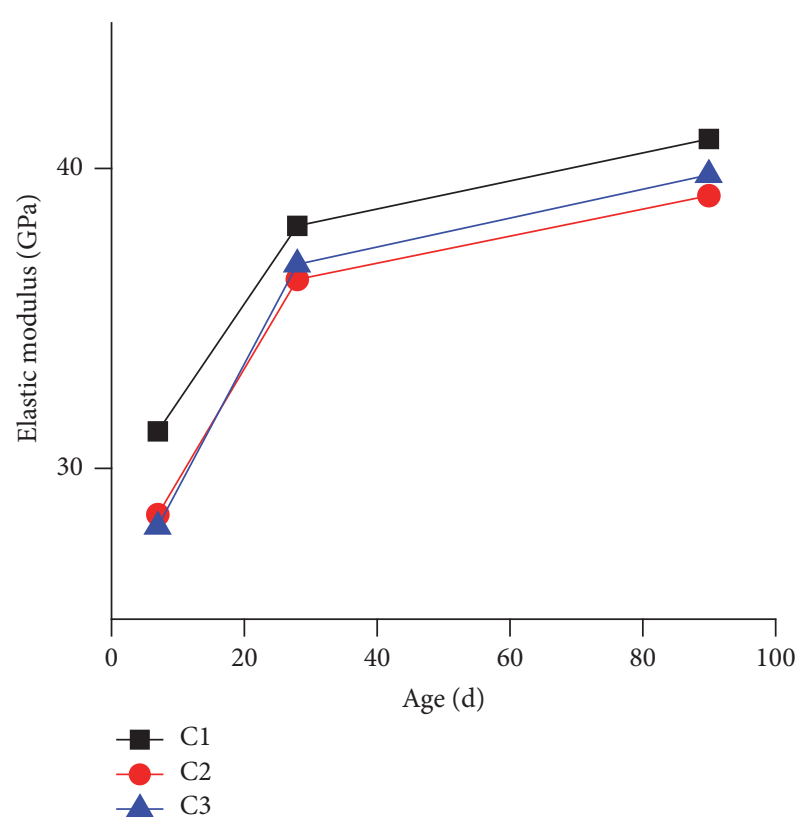

(a)

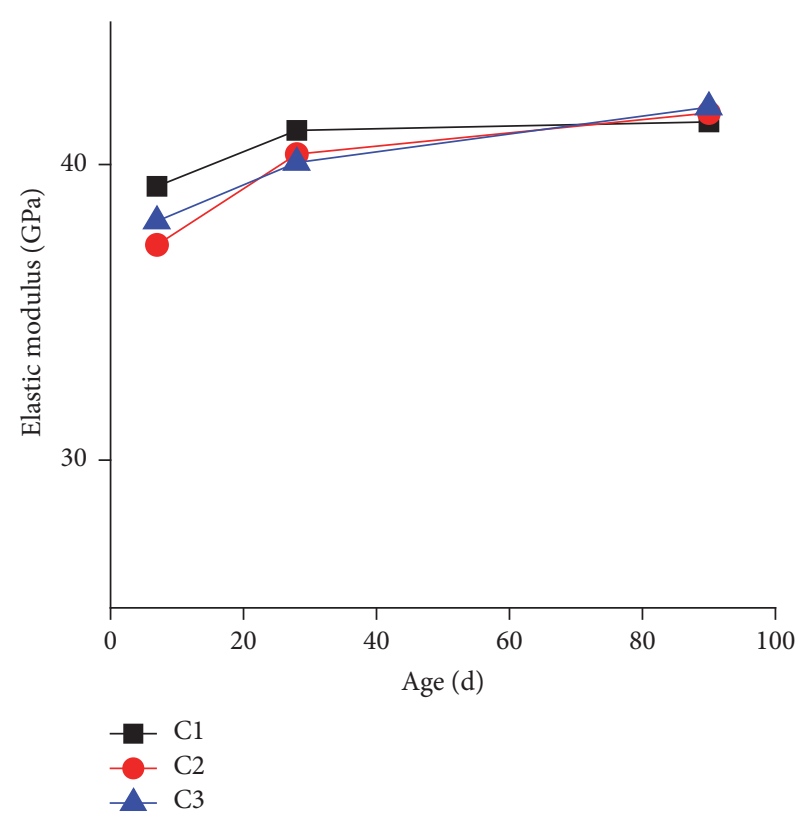

(b)

FIGURE 6: (a) Elastic modulus of concrete under standard curing. (b) Elastic modulus of concrete under temperature match curing.

than that for plain cement concrete for standard curing. However, the charge passed for concrete containing the composite mineral admixture for temperature match curing is less than that for concrete containing composite mineral admixture for standard curing. It is noteworthy that the chloride ion permeability grade of the concrete containing $50 \%$ composite mineral admixture B is "Very low" and the addition of $50 \%$ composite mineral admixture B improves the resistance to chloride ion permeability for the concrete by two levels. These results indicate that high temperatures have a negative effect on the resistance to chloride ion permeability in plain cement concrete, whereas the improvement effect of composite mineral admixture on the resistance to chloride ion permeability is enhanced at high temperatures. Therefore, the concrete containing the composite mineral admixture obtains satisfactory resistance to chloride ion permeability 

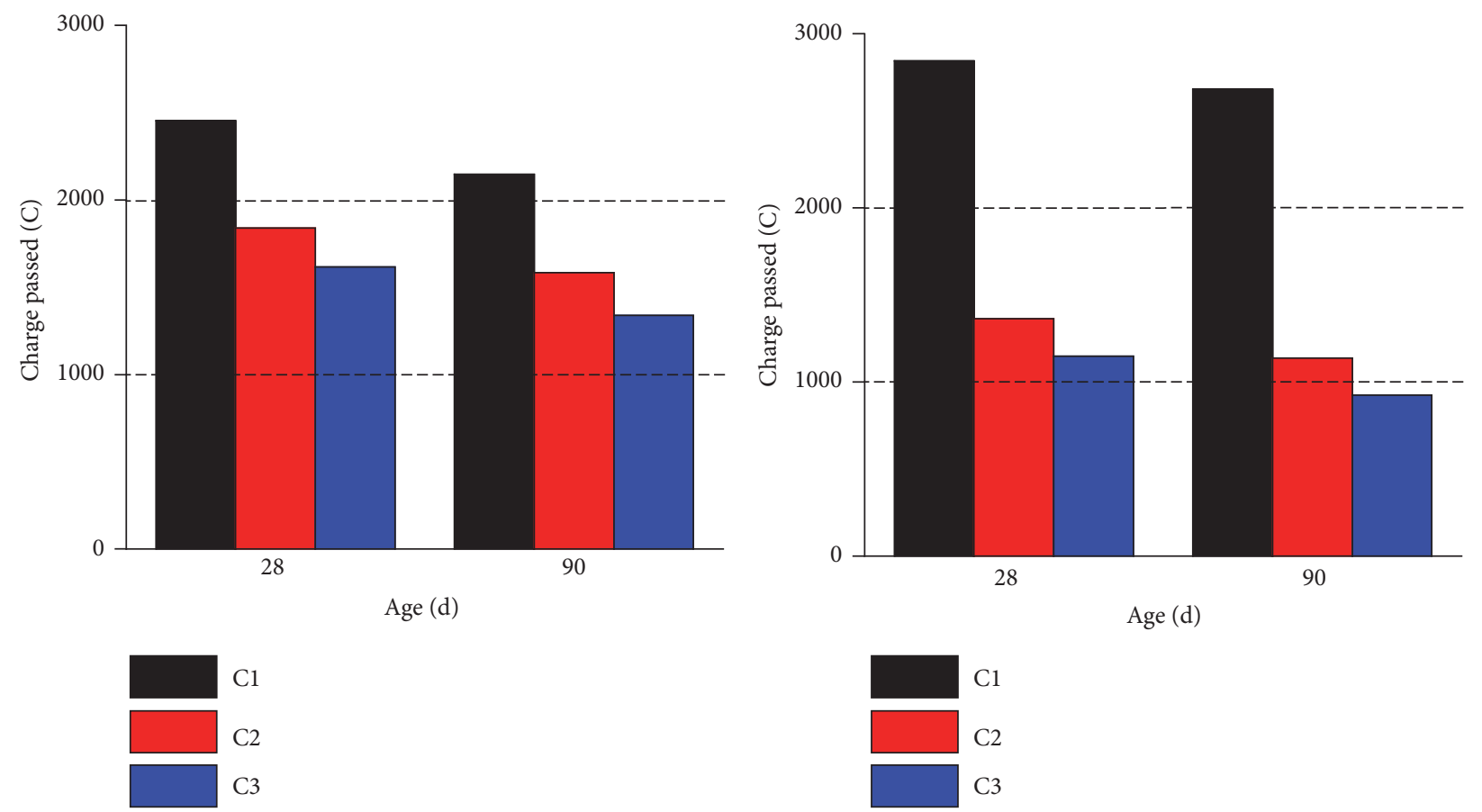

(a)

(b)

FIGURE 7: (a) Chloride ion permeability for the concrete for standard curing. (b) Chloride ion permeability for the concrete for temperature match curing.

when using temperature match curing. This is because the hydration degree of the mineral admixture increases at high temperature, as a result of which the pore structure of hardened paste is denser and the resistance to chloride ion permeability of concrete improves [26, 27, 29].

3.4. Sulphate Attack Resistance. Figure 8(a) shows the compressive strength of the concrete during a sulphate attack test when using standard curing. After 90 dry-wet cycles, the compressive strength of plain cement concrete exposed to sulphate attack decreases by $10.7 \%$ compared to concrete at $28 \mathrm{~d}$. The strength loss rate of plain cement concrete is $21.0 \%$. However, the compressive strengths of concrete containing $50 \%$ composite mineral admixtures $\mathrm{A}$ and $\mathrm{B}$ exposed to sulphate attack increase by $6.5 \%$ and $6.7 \%$, respectively, compared to concrete at $28 \mathrm{~d}$. Additionally, the strength loss rates for concrete containing $50 \%$ composite mineral admixtures A and B are only $15.0 \%$ and $13.0 \%$, respectively. After 120 dry-wet cycles, the strength loss rate for the plain cement concrete is $37.9 \%$, whereas the strength loss rates for concrete containing 50\% composite mineral admixtures A and $\mathrm{B}$ are only $27.7 \%$ and $25.0 \%$, respectively. These results indicate that the composite mineral admixture can improve concrete sulphate attack resistance significantly. In addition, the GGBS content of composite mineral admixture $B$ is higher than that of composite mineral admixture $\mathrm{A}$, and the improvement effect of composite mineral admixture $B$ on the sulphate attack resistance for concrete is greater than that of composite mineral admixture A. This could be explained that the pozzolanic reaction of GGBS consumes $\mathrm{Ca}(\mathrm{OH})_{2}$, leading to the reduction of the gypsum formation, and thus of ettringite [30].

Figure 8(b) shows the compressive strength of the concrete during a sulphate attack test when using temperature match curing. As shown in Figure 8(b), after 90 dry-wet cycles, the compressive strength of plain cement concrete exposed to sulphate attack is nearly the same as concrete at $28 \mathrm{~d}$, and the strength loss rate for plain cement concrete is $22.5 \%$. However, the compressive strengths of the concrete containing $50 \%$ composite mineral admixtures $\mathrm{A}$ and $\mathrm{B}$ exposed to sulphate attack increase by $26.0 \%$ and $29.5 \%$ compared to concrete at $28 \mathrm{~d}$, and the strength loss rates of concrete containing 50\% composite mineral admixtures A and B are only $12.9 \%$ and $11.4 \%$, respectively. After 120 drywet cycles, the strength loss rate for the plain cement concrete is $40.4 \%$, whereas the strength loss rates for the concrete containing $50 \%$ composite mineral admixtures $\mathrm{A}$ and $\mathrm{B}$ are only $25.0 \%$ and $23.0 \%$, respectively. These results indicate that the composite mineral admixtures can still significantly improve the sulphate attack resistance of concrete when using temperature match curing and the improvement effect of composite mineral admixture B is stronger than that of composite mineral admixture A. It is worth noting that the strength loss rate for the plain cement concrete increases compared to concrete using standard curing, whereas the strength loss rate for the concrete containing composite mineral admixture decreases compared with standard cured concrete, indicating that high temperatures have a negative effect on the sulphate attack resistance of plain cement concrete. However, the improvement effect of composite mineral 


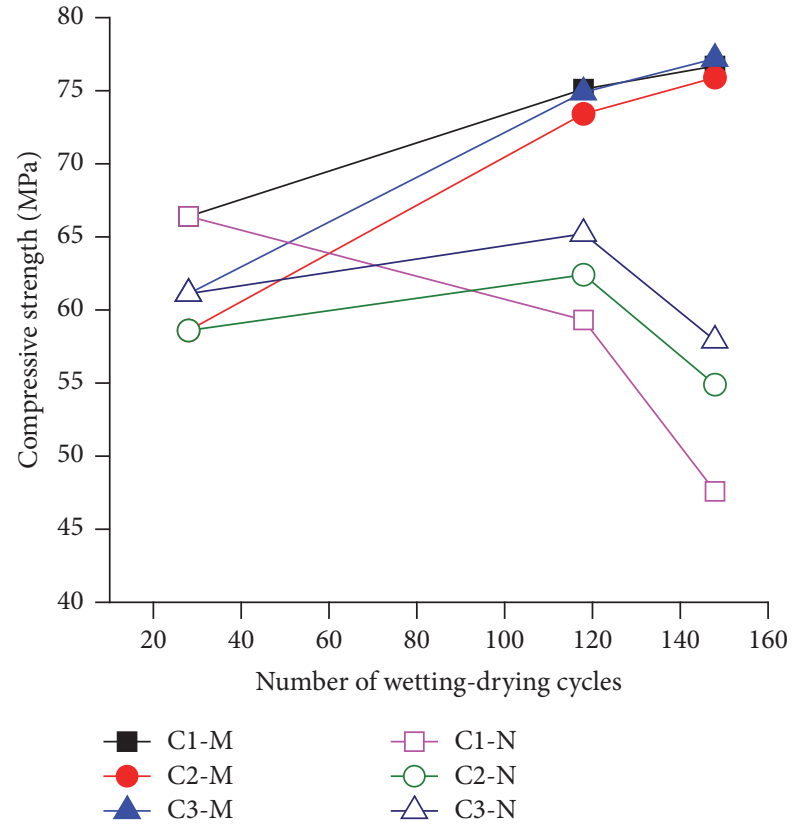

(a)

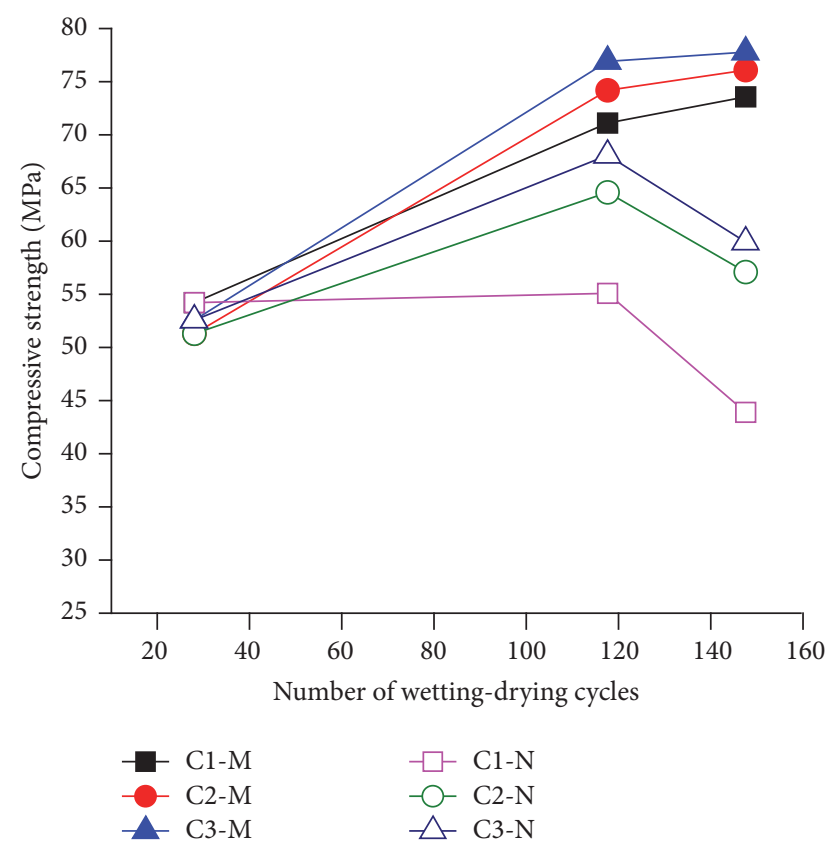

(b)

FIGURE 8: (a) Compressive strength of the concrete during a sulphate attack test when using standard curing. (b) Compressive strength of the concrete during a sulphate attack test when using temperature match curing.

admixture on the sulphate attack resistance is enhanced at high temperatures, and the concrete containing composite mineral admixture results in a satisfactory sulphate attack resistance for temperature match curing. These results are consistent with those from the chloride ion permeability test.

\section{Conclusions}

(1) The addition to granulate blast furnace slag-steel slag composite binder can reduce the hydration heat of the composite binder at $20^{\circ} \mathrm{C}$. However, the hydration heat of the composite binder is decreased greatly only when the cement replacement ratio increases to $50 \%$ at $45^{\circ} \mathrm{C}$. Therefore, the addition of the composite mineral admixture applied in massive concrete should be $50 \%$.

(2) For either $28 \mathrm{~d}$ or $90 \mathrm{~d}$, the addition of $50 \%$ composite mineral admixture can decrease the early elastic modulus of the concrete, which is helpful to decrease the risk of thermally induced cracking. In addition, the concrete containing 50\% composite mineral admixture possesses satisfactory late-age compressive strength.

(3) The addition of 50\% composite mineral admixture can improve the resistance to chloride ion permeability and the sulphate attack resistance of concrete, especially when using temperature match curing.

(4) Although the composite mineral admixture with a GGBS to steel slag mass ratio of $3: 2$ increases the adiabatic temperature rise by $2.7^{\circ} \mathrm{C}$ within $7 \mathrm{~d}$ compared to the composite mineral admixture with a
GGBS to steel slag mass ratio of $1: 1$, the compressive strength, resistance to chloride ion permeability, and sulphate attack resistance of the concrete containing the composite mineral admixture with a GGBS to steel slag mass ratio of $3: 2$ are significantly higher.

\section{Conflicts of Interest}

The authors declare that there are no conflicts of interest regarding the publication of this paper.

\section{Acknowledgments}

The support of China National Natural Science Foundation Project (no. 51572293) is acknowledged.

\section{References}

[1] X. Liu, C. Zhang, X. Chang, W. Zhou, Y. Cheng, and Y. Duan, "Precise simulation analysis of the thermal field in mass concrete with a pipe water cooling system," Applied Thermal Engineering, vol. 78, no. 5, pp. 449-459, 2015.

[2] M. E. Shabab, K. Shahzada, B. Gencturk, M. Ashraf, and M. Fahad, "Synergistic effect of fly ash and bentonite as partial replacement of cement in mass concrete," KSCE Journal of Civil Engineering, vol. 20, no. 5, pp. 1987-1995, 2016.

[3] M. Batog and Z. Giergiczny, "Influence of mass concrete constituents on its properties," Construction and Building Materials, vol. 146, pp. 221-230, 2017.

[4] H. N. Atahan and D. Dikme, "Use of mineral admixtures for enhanced resistance against sulfate attack," Construction and Building Materials, vol. 25, no. 8, pp. 3450-3457, 2011. 
[5] M. Najjar, M. Nehdi, A. Soliman, and T. Azabi, "Damage mechanisms of two-stage concrete exposed to chemical and physical sulfate attack," Construction and Building Materials, vol. 137, pp. 141-152, 2017.

[6] C. Shi, "Steel slag-its production, processing, characteristics, and cementitious properties," Journal of Materials in Civil Engineering, vol. 16, no. 3, pp. 230-236, 2004.

[7] E. Furlani, G. Tonello, and S. Maschio, "Recycling of steel slag and glass cullet from energy saving lamps by fast firing production of ceramics," Waste Management, vol. 30, no. 8-9, pp. 1714-1719, 2010.

[8] J. Li, Q. Yu, J. Wei, and T. Zhang, "Structural characteristics and hydration kinetics of modified steel slag," Cement and Concrete Research, vol. 41, no. 3, pp. 324-329, 2011.

[9] S. Liu and L. Li, "Influence of fineness on the cementitious properties of steel slag," Journal of Thermal Analysis and Calorimetry, vol. 117, no. 2, pp. 629-634, 2014.

[10] S. Mengxiao, W. Qiang, and Z. Zhikai, "Comparison of the properties between high-volume fly ash concrete and highvolume steel slag concrete under temperature matching curing condition," Construction and Building Materials, vol. 98, pp. 649-655, 2015.

[11] Q. Wang and P. Yan, "Hydration properties of basic oxygen furnace steel slag," Construction and Building Materials, vol. 24, no. 7, pp. 1134-1140, 2010.

[12] T. Zhang, Q. Yu, J. Wei, and J. Li, "Investigation on mechanical properties, durability and micro-structural development of steel slag blended cements," Journal of Thermal Analysis and Calorimetry, vol. 110, no. 2, pp. 633-639, 2012.

[13] J. Hu, "Comparison between the effects of superfine steel slag and superfine phosphorus slag on the long-term performances and durability of concrete," Journal of Thermal Analysis and Calorimetry, vol. 128, no. 3, pp. 1251-1263, 2017.

[14] Q. Wang, P. Yan, and G. Mi, "Effect of blended steel slagGBFS mineral admixture on hydration and strength of cement," Construction and Building Materials, vol. 35, pp. 8-14, 2012.

[15] J. Zhao, D. Wang, and P. Yan, "Design and experimental study of a ternary blended cement containing high volume steel slag and blast-furnace slag based on Fuller distribution model," Construction and Building Materials, vol. 140, pp. 248-256, 2017.

[16] A. Attari, C. McNally, and M. G. Richardson, "A combined SEM - Calorimetric approach for assessing hydration and porosity development in GGBS concrete," Cement and Concrete Composites, vol. 68, pp. 46-56, 2016.

[17] E. Özbay, M. Erdemir, and H. I. Durmuş, "Utilization and efficiency of ground granulated blast furnace slag on concrete properties - A review," Construction and Building Materials, vol. 105, pp. 423-434, 2016.

[18] Y. Ballim and P. C. Graham, "The effects of supplementary cementing materials in modifying the heat of hydration of concrete," Materials and Structures/Materiaux et Constructions, vol. 42, no. 6, pp. 803-811, 2009.

[19] Q. Wang, M. Li, and G. Jiang, "The difference among the effects of high-temperature curing on the early hydration properties of different cementitious systems," Journal of Thermal Analysis and Calorimetry, vol. 118, no. 1, pp. 51-58, 2014.

[20] F. Han, R. Liu, D. Wang, and P. Yan, "Characteristics of the hydration heat evolution of composite binder at different hydrating temperature," Thermochimica Acta, vol. 586, pp. 5257, 2014.
[21] P. Šiler, J. Krátký, I. Kolářová, J. Havlica, and J. Brandštetr, "Calorimetric determination of the effect of additives on cement hydration process," Chemical Papers, vol. 67, no. 2, pp. 213-220, 2013.

[22] M. S. Morsy, "Effect of temperature on electrical conductivity of blended cement pastes," Cement and Concrete Research, vol. 29, no. 4, pp. 603-606, 1999.

[23] S. C. Pal, A. Mukherjee, and S. R. Pathak, "Investigation of hydraulic activity of ground granulated blast furnace slag in concrete," Cement and Concrete Research, vol. 33, no. 9, pp. 14811486, 2003.

[24] E. Gallucci, X. Zhang, and K. L. Scrivener, "Effect of temperature on the microstructure of calcium silicate hydrate (C-S-H)," Cement and Concrete Research, vol. 53, pp. 185-195, 2013.

[25] K. O. Kjellsen, R. J. Detwiler, and O. E. Gjørv, "Development of microstructures in plain cement pastes hydrated at different temperatures," Cement and Concrete Research, vol. 21, no. 1, pp. 179-189, 1991.

[26] J. Liu and D. Wang, "The Role of Phosphorus Slag in SteamCured Concrete," Advances in Materials Science and Engineering, vol. 2017, Article ID 8392435, 14 pages, 2017.

[27] M. Li, Q. Wang, and J. Yang, "Influence of Steam Curing Method on the Performance of Concrete Containing a Large Portion of Mineral Admixtures," Advances in Materials Science and Engineering, vol. 2017, Article ID 9863219, 11 pages, 2017.

[28] A. Hadj-Sadok, S. Kenai, L. Courard, and A. Darimont, "Microstructure and durability of mortars modified with medium active blast furnace slag," Construction and Building Materials, vol. 25, no. 2, pp. 1018-1025, 2011.

[29] H. Jin, "Late-Age Properties of Concrete with Different Binders Cured under $45 \circ \mathrm{C}$ at Early Ages," Advances in Materials Science and Engineering, vol. 2017, pp. 1-13, 2017.

[30] A. Hadjsadok, S. Kenai, L. Courard, F. Michel, and J. Khatib, "Durability of mortar and concretes containing slag with low hydraulic activity," Cement and Concrete Composites, vol. 34, no. 5, pp. 671-677, 2012. 

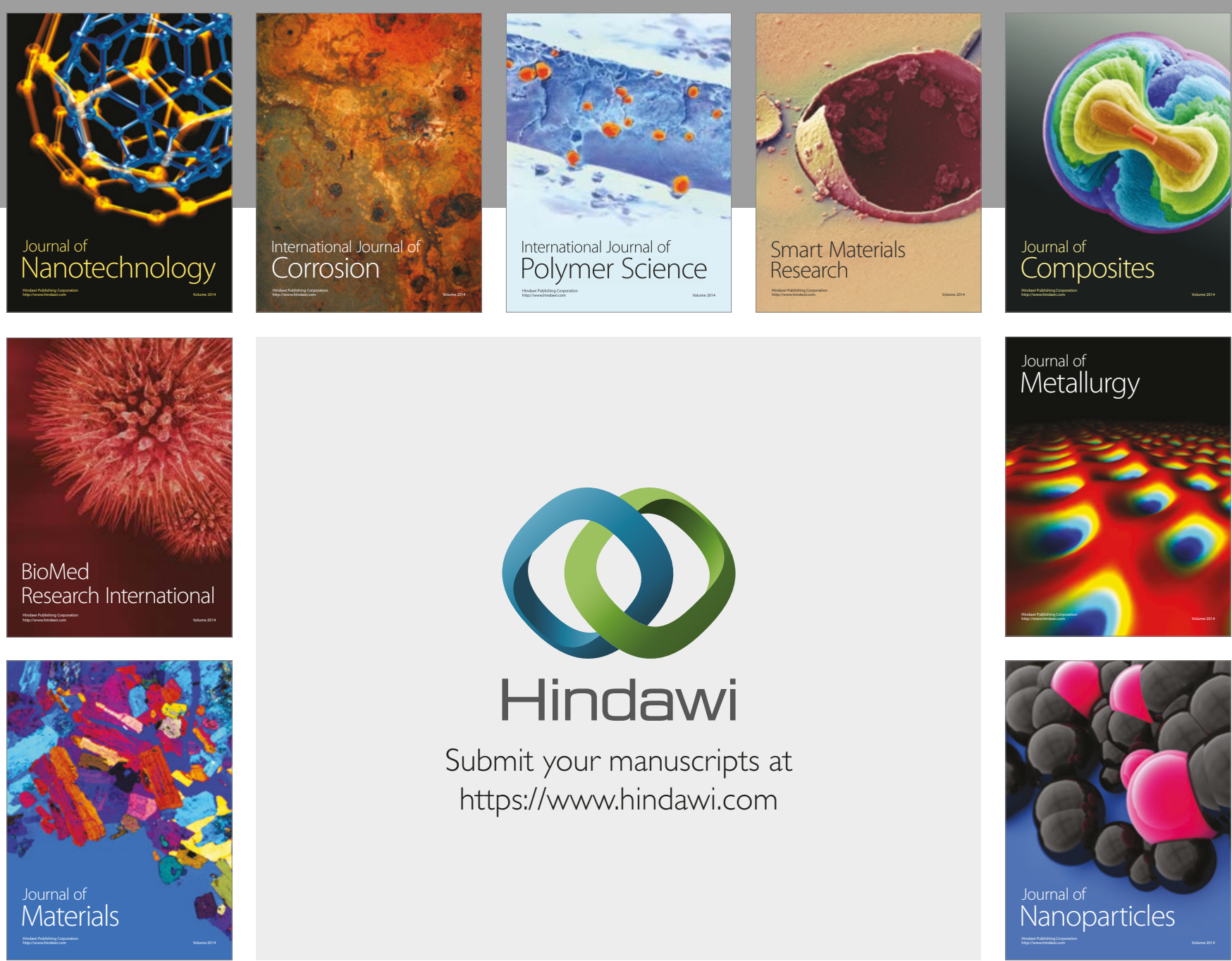

\section{Hindawi}

Submit your manuscripts at

https://www.hindawi.com
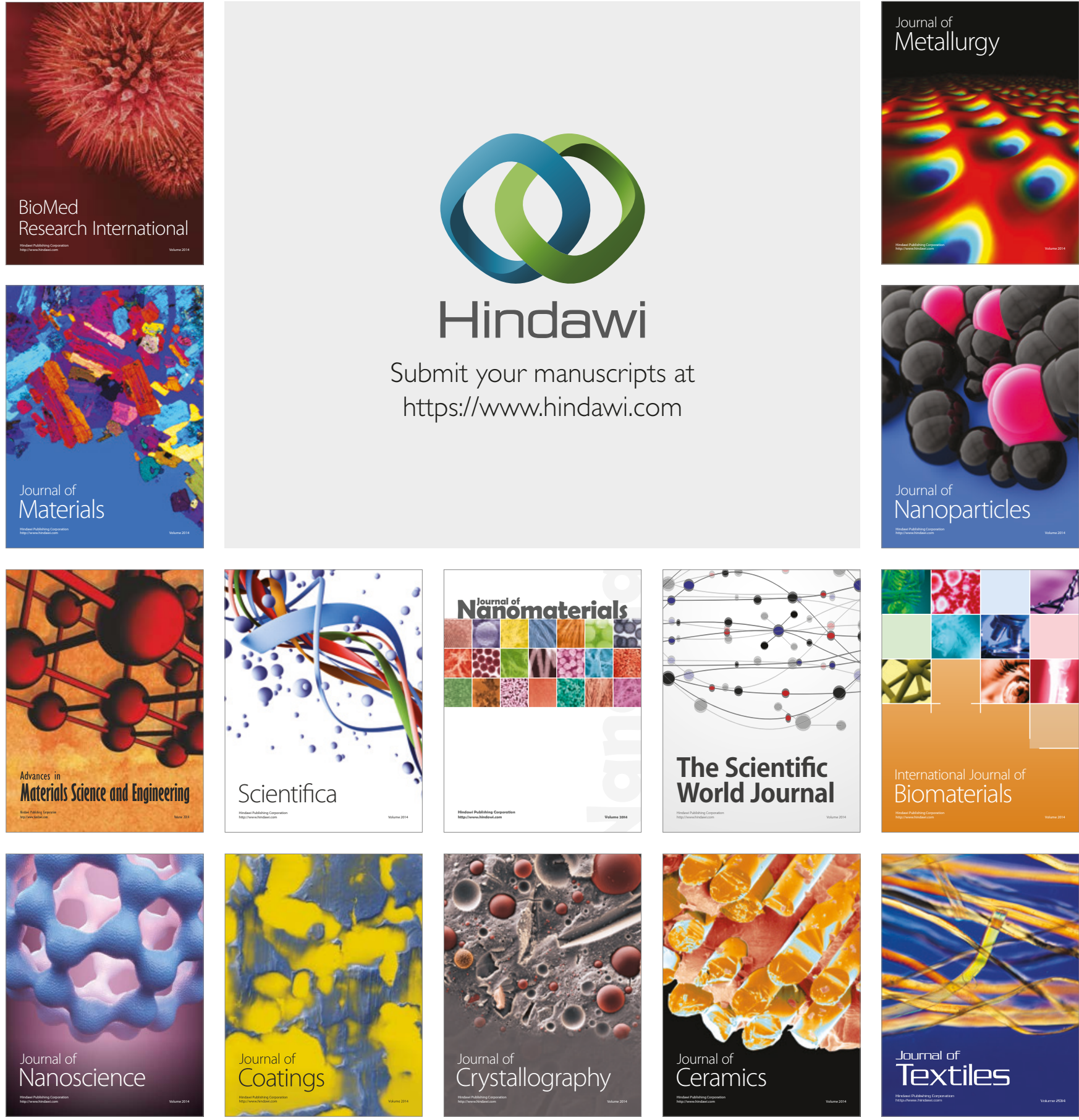

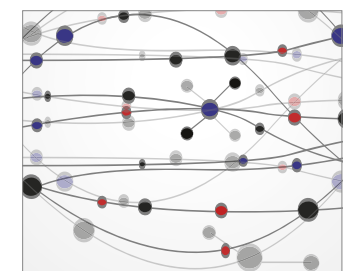

The Scientific World Journal
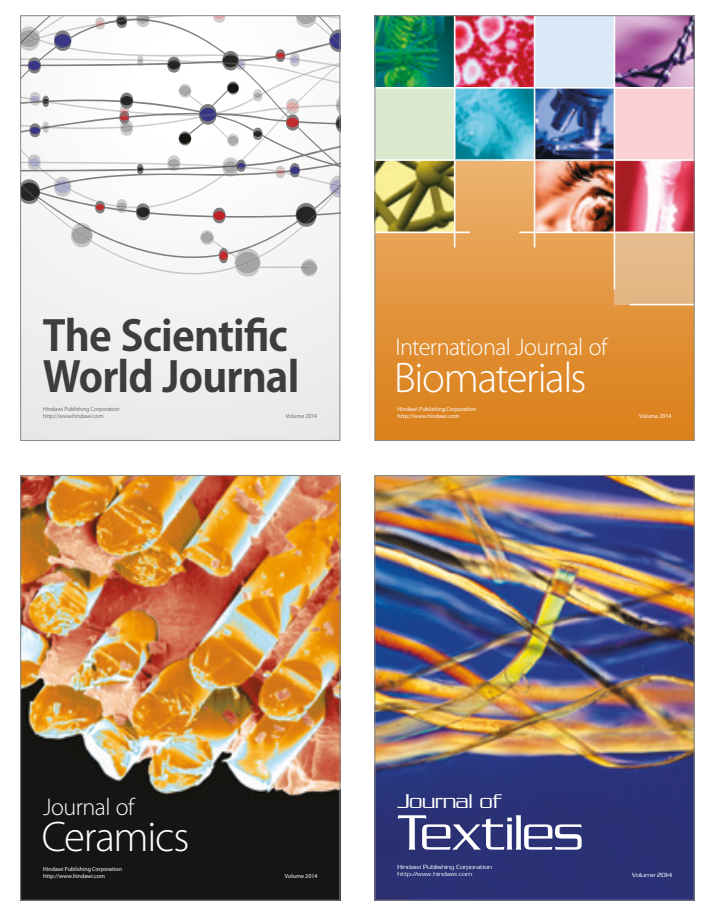